\title{
HRAS as a potential therapeutic target of salirasib RAS inhibitor in bladder cancer
}

\author{
SATOSHI SUGITA* , HIDEKI ENOKIDA*, HIROFUMI YOSHINO, KAZUTAKA MIYAMOTO, MASAYA YONEMORI, \\ TAKASHI SAKAGUCHI, YOICHI OSAKO and MASAYUKI NAKAGAWA
}

Department of Urology, Graduate School of Medical and Dental Sciences, Kagoshima University, Kagoshima, Kagoshima 890-8520, Japan

Received January 26, 2018; Accepted May 10, 2018

DOI: $10.3892 /$ ijo.2018.4435

\begin{abstract}
The active form of the small GTPase RAS binds to downstream effectors to promote cell growth and proliferation. RAS signal enhancement contributes to tumorigenesis, invasion, and metastasis in various different cancers. HRAS proto-oncogene GTPase (HRAS), one of the RAS isoforms, was the first human oncogene for which mutations were reported in T24 bladder cancer (BC) cells in 1982, and HRAS mutation or upregulation has been reported in several cancers. According to data from The Cancer Genome Atlas, HRAS expression was significantly upregulated in clinical BC samples compared to healthy samples $(\mathrm{P}=0.0024)$. HRAS expression was also significantly upregulated in BC with HRAS mutation compared to patients without HRAS mutation $(\mathrm{P}<0.0001)$. The tumor suppressive effect of salirasib, a RAS inhibitor, has been reported in several cancer types, but only at relatively high concentrations. As such, RAS inhibitors have not been used for clinical applications. The aim of the current study was to investigate the therapeutic potential of targeting HRAS using salirasib and small interfering RNA (siRNA) and to characterize the mechanism by which HRAS functions using recently developed quantitative in vitro proteome-assisted multiple reaction monitoring for protein absolute quantification (iMPAQT), in BC cells. iMPAQT allows measurement of the absolute abundance of any human protein with the high quantitative accuracy. Salirasib and siRNA targeting of HRAS inhibited cell proliferation, migration and invasion in HRAS wild type and HRAS-mutated cell lines. Proteomic analyses revealed that several metabolic pathways, including the oxida-
\end{abstract}

Correspondence to: Dr Hirofumi Yoshino, Department of Urology, Graduate School of Medical and Dental Sciences, Kagoshima University, 8-35-1 Sakuragaoka, Kagoshima, Kagoshima 890-8520, Japan

E-mail: hyoshino@m3.kufm.kagoshima-u.ac.jp

*Contributed equally

Key words: bladder cancer, HRAS proto-oncogene GTPase, RAS inhibitor, salirasib, in vitro proteome-assisted multiple reaction monitoring for protein absolute quantification tive phosphorylation pathway and glycolysis, were significantly downregulated in salirasib-treated BC cells. However, the expression levels of hexokinase 2, phosphoglycerate kinase 1, pyruvate kinase, muscle (PKM)1, PKM2 and lactate dehydrogenase $\mathrm{A}$, which are downstream of RAS and target genes of hypoxia inducible factor-1 $\alpha$, were not notably downregulated, which may explain the high concentration of salirasib required to inhibit cell viability. These findings provide insight into the mechanisms of salirasib, and suggest the need for novel therapeutic strategies to treat cancers such as BC.

\section{Introduction}

Bladder cancer (BC) was the 5th most commonly diagnosed cancer and the 8th most common cause of cancer-associated mortality among the 40 European Union countries in 2012. In that same year, 429,800 new cases of BC were diagnosed, and 165,000 patients succumbed to $\mathrm{BC}$ worldwide $(1,2)$. The 5-year survival rate of patients with $\mathrm{BC}$ has improved by only a small percentage during the last 30 years according to the National Cancer Institute program Surveillance, Epidemiology and End Results (3). One factor in the lack of improvement in BC survival rates is the limited efficacy of cisplatin-based combination chemotherapy (4). Thus, innovative therapeutic strategies are required to improve BC outcomes.

RAS proteins are small molecular weight GTPases that couple extracellular signals to intracellular effector pathways. Mammalian cells encode three closely related RAS proteins, HRas proto-oncogene GTPase (HRAS), NRAS protooncogene GTPase (NRAS) and KRAS proto-oncogene GTPase (KRAS), which have critical roles in fundamental cellular processes, including proliferation, survival, differentiation, motility and transcription (5). The RAS pathway is one of the most commonly deregulated pathways in human cancer (6), and activating mutations in RAS genes occur in $\sim 30 \%$ of all tumors (7). These mutations typically render RAS as constitutively GTP-bound, resulting in activation of downstream effector pathways regardless of extracellular stimulation (6). Substitution of glycine for valine at amino acid 12 (G12V) is one of the most frequently observed RAS mutations that interferes with GTPase-activating protein-mediated GTP hydrolysis, leading to excess amounts of active GTP-bound RAS. Notably, the type of mutated RAS gene (HRAS, KRAS or 
$N R A S$ ) varies depending on the tumor type; KRAS mutations are frequently detected in pancreatic carcinoma (80-90\%) and colorectal carcinoma (30-60\%), whereas HRAS mutations are frequent in BC (7-66\%) and thyroid cancer (0-60\%) (8).

RAS is considered 'undruggable' because the RAS protein lacks a druggable binding pocket $(9,10)$. Additionally, development of specific and competitive nucleotide inhibitors is challenging, because RAS binds nucleotide ligands with high affinity (10). To overcome these challenges, the RAS antagonist salirasib, also termed farnesylthiosalicylate, was designed to competitively inhibit attachment of GTP-bound RAS to the plasma membrane, which in turn inactivates RAS signaling (11). Salirasib inhibits all RAS isoforms and inhibits the growth of RAS-driven cancer $(11,12)$. Although applications of salirasib have been tested in several clinical trials for cancers other than BC (13-16), it exhibited insufficient tumor suppressive effects in trials in which salirasib was the single agent. In addition, relatively high concentrations of salirasib were required to achieve sufficient tumor suppressive effects $(17,18)$. Therefore, a more detailed examination of the effects of salirasib is required to understand the mechanism by which salirasib acts on RAS. Recently, Matsumoto et al (19) developed a targeted proteomics platform, in vitro proteomeassisted multiple reaction monitoring for protein absolute quantification (iMPAQT), that analyzes 18,000 human recombinant proteins to enable absolute protein quantification on a genome-wide scale (19) and overcome limitations in quantitative accuracy, reproducibility, and analysis speed associated with conventional analysis methods. Use of iMPAQT allows large-scale and accurate assessment of protein abundances that can influence cellular phenotypes.

In the current study, the therapeutic of potential of $H R A S$ knockdown by salirasib or RNA interference was investigated in two BC cell lines (T24 cells with HRAS G12V mutation and BOY cells without HRAS mutation). Furthermore, newly developed quantitative proteome analysis of $\mathrm{BC}$ cells treated with salirasib was performed to elucidate the mechanisms underlying the actions of salirasib toward HRAS.

\section{Materials and methods}

Analysis in the BC cohort of The Cancer Genome Atlas (TCGA). Sequencing data were available for $407 \mathrm{BC}$ samples and 19 normal bladder epithelial samples in TCGA database (tcga-data.nci.nih. gov/tcga/). We used TCGA to analyze HRAS mRNA expression levels in normal and $\mathrm{BC}$ tissues and to evaluate differences in $H R A S$ mRNA expression levels according to HRAS mutational status. RNA-Seq by Expectation Maximization software was used for gene expression quantification (20). Full sequencing information, somatic mutation information, and clinical information were acquired using UCSC Xena (xena.ucsc.ed/) and TCGA. The current study meets publication guidelines provided by TCGA (cancergenome.nih.gov/publications/publicationguidelines).

Cell culture and RNA extraction. Four human BC cell lines were used. T24, KK47 and UMUC cells, which were obtained from the American Type Culture Collection (Manassas, VA, USA), and BOY cells, which were established in our laboratory from a 66-year-old Asian male patient diagnosed with stage III BC with lung metastasis. These cell lines were maintained in the minimum essential Eagle's medium (Sigma-Aldrich; Merck KGaA, Darmstadt, Germany), containing 10\% fetal bovine serum (Equitech-Bio, Inc., Kerrville, TX, USA), $50 \mu \mathrm{g} / \mathrm{ml}$ streptomycin, and $50 \mathrm{U} / \mathrm{ml}$ penicillin in a humidified atmosphere of $95 \%$ air $/ 5 \% \mathrm{CO}_{2}$ at $37^{\circ} \mathrm{C}$. Total RNA was isolated using Isogen (Nippon Gene Co., Ltd., Tokyo, Japan) according to the manufacturer's protocol. The integrity of the RNA was checked with an RNA 6000 Nano assay kit and a 2100 Bioanalyzer (Agilent Technologies, Inc., Santa Clara, CA, USA).

Reverse transcription-quantitative polymerase chain reaction $(R T-q P C R)$. A SYBR-Green qPCR-based array approach was used for RT-qPCR. RT was performed using the TaqMan HighCapacity cDNA Reverse Transcription Kit (cat. no. 4368814; Applied Biosystems; Thermo Fisher Scientific, Inc., Waltham, MA, USA) under the incubation conditions $\left(25^{\circ} \mathrm{C}\right.$ for $10 \mathrm{~min}$, $37^{\circ} \mathrm{C}$ for $120 \mathrm{~min}$ and $85^{\circ} \mathrm{C}$ for $5 \mathrm{~min}$ ) according to the manufacturer's instructions. The primer set for determination of mRNA expression levels was as follows: $H R A S$, forward, 5'-ATGACGGAATATAAGCTGGTGGT-3' and reverse, 5'-GGCACGTCTCCCCATCAATG-3'; hypoxia inducible factor- $1 \alpha(H I F-1 \alpha)$, forward, 5'-GAACGTCGAAAAGAAAA GTCTCG-3' and reverse, 5'-CCTTATCAAGATGCGAACTC ACA-3'; glucuronidase $\beta$ (GUSB), forward, 5'-CGTCCCACC TAGAATCTGCT-3' and reverse, 5'-TTGCTCACAAAGGT CACAGG-3'. The experimental procedures followed the protocol recommended by the manufacturer. RT-qPCR was performed with 500 ng total RNA using the Power SYBR-Green Master Mix (cat. no. 4367659) with the 7300 Real-time PCR System (both from Applied Biosystems; Thermo Fisher Scientific, Inc.). Amplification specificity was monitored using the dissociation curve of the amplified product. All data values were normalized with respect to GUSB, and the $\Delta \Delta \mathrm{Cq}$ method was used to calculate the fold-change (21). Human Bladder Total RNA (cat. no. AM7990; Applied Biosystems; Thermo Fisher Scientific, Inc.) as control RNA derived from normal bladder tissue.

Salirasib treatment. For in vitro experiments, salirasib (CAS 162520-00-5; Santa Cruz Biotechnology, Inc., Dallas, TX, USA) was solubilized in $0.1 \%$ DMSO. The salirasib/DMSO solution and control vehicle (0.1\% DMSO) were prepared in Dulbecco's modified Eagle's medium at different concentrations, and each mixture was placed in cell culture plates $\left(8 \times 10^{4} / \mathrm{ml}\right)$ so that the final salirasib concentrations were 1.6, $3.1,6.3,12.5,25,50,100$ and $200 \mu \mathrm{M}$, whereas the DMSO concentration was adjusted to $0.1 \%$. Each cell culture plate was treated with salirasib or control vehicle for $24 \mathrm{~h}$. For in vivo experiments, salirasib was solubilized with $0.5 \%$ ethanol. The salirasib/ethanol solution was alkalinized with $1 \mathrm{~N} \mathrm{NaOH}$ and then diluted with phosphate buffered saline to yield a $4 \mathrm{mg} / \mathrm{ml}(\mathrm{pH} 8.0)$ solution. This solution or control vehicle (0.5\% ethanol) were intraperitoneally (i.p.) injected daily $100 \mu 1$ per mouse.

Transfection with small interfering RNA (siRNA). As described previously (22), T24 and BOY cells were transfected using Lipofectamine RNAiMAX transfection reagent and Opti-MEM (both from Thermo Fisher Scientific, Inc.) together with $10 \mathrm{nM}$ 
HRAS siRNA (nos. Hs_HRAS_1174, Hs_HRAS_1177 and Hs_HRAS_1178; Sigma-Aldrich; Merck KGaA) or negativecontrol siRNA (no. D-001810-10; Thermo Fisher Scientific, Inc.) for loss-of-function experiments. The sequences of the siRNAs were as follows: Hs_HRAS_1174_s, 5'rGUrGrCrCUrGUUrGr GrArCrAUrCrCUrGTT; Hs_HRAS_1174_as, 5'rCrArGrGr AUrGUrCrCrArArCrArGrGrCrArCTT; Hs_HRAS_1177_s, 5 'rGrArCrGUrGrCrCUrGUUrGrGrArCrAUrCTT; Hs HRAS_1177_as, 5'rGrAUrGUrCrCrArArCrArGrGrCrArCr GUrCTT; Hs_HRAS_1178_s, 5'rGrGrGrCUUrCrCUrGUrGU rGUrGUUUTT; and Hs_HRAS_1178_as, 5'rArArArCrArCrAr CrArCrArGrGrArArGrCrCrCTT. Subsequent experiments were performed $72 \mathrm{~h}$ after siRNA transfection.

Cell proliferation, migration, and invasion assays. T24 and BOY cells were transfected with $10 \mathrm{nM}$ siRNA by reverse transfection. Cells were seeded in 96-well plates with $3 \times 10^{3}$ cells/well for XTT assays. After $72 \mathrm{~h}$, cell proliferation was determined using a Cell Proliferation Kit II (Roche Diagnostics GmbH, Mannheim, Germany) as described previously (22). Cell migration activity was evaluated with wound healing assays. Cells were plated in 6 -well plates at $2 \times 10^{5}$ cells per well, and after $48 \mathrm{~h}$ of transfection the cell monolayer was scraped using a P-20 micropipette tip. The initial $(0 \mathrm{~h})$ and residual gap length $18 \mathrm{~h}$ after wounding were calculated from photomicrographs as previously described (22). Cell invasion assays were performed using modified Boyden chambers consisting of Matrigel-coated Transwell membrane filter inserts with $8-\mu \mathrm{M}$ pores in 24 well tissue culture plates (BD Biosciences, San Jose, CA, USA). At $72 \mathrm{~h}$ after transfection, cells were plated in 24 -well plates at $1 \times 10^{5}$ cells/well. Minimum essential Eagle's medium containing $10 \%$ fetal bovine serum (Equitech-Bio, Inc.) in the lower chamber served as the chemoattractant, as described previously (22). Medium Eagle fetal bovine serum and cells were prepared in the upper chamber and incubated for $24 \mathrm{~h}$.

Western blot analysis. Cells were harvested $72 \mathrm{~h}$ after transfection, and lysates were prepared in radioimmunoprecipitation assay lysis buffer (Thermo Fisher Scientific, Inc.) containing protease inhibitor cocktail (Sigma-Aldrich; Merck KGaA). Proteins were quantified by Bradford method using BioPhotometer (Eppendorf, Hamburg, Germany). Proteins $(50 \mu \mathrm{g})$ were separated by NuPAGE on $4-12 \%$ bis-tris gels (Invitrogen; Thermo Fisher Scientific, Inc.) and transferred to polyvinylidene difluoride membranes. Following blocking in Tris-buffered saline containing $0.1 \%$ Tween-20 (TBS-T) with $5 \%$ nonfat dry milk for $15 \mathrm{~min}$ at $25^{\circ} \mathrm{C}$, membranes were washed four times in TBS-T and incubated with primary antibodies overnight at $4^{\circ} \mathrm{C}$. Immunoblotting was performed with diluted rabbit polyclonal anti-HRAS antibodies (1:1,000; cat. no. GTX116041; GeneTex, Inc., Irvine, CA, USA), goat polyclonal anti-HIF-1 $\alpha$ antibodies (1:1,000; cat. no. AF1935; R\&D Systems, Inc., Minneapolis, MN, USA) and rabbit polyclonal anti- $\beta$-actin antibodies (1:1,000; cat. no. bs-0061R; BIOSS, Beijing, China) according to the manufacturer's instructions for each antigen. The secondary antibodies were peroxidase-labelled anti-rabbit $\operatorname{IgG}\left(1 \mathrm{~h}\right.$ at $25^{\circ} \mathrm{C} ; 1: 5,000$; cat. no. 7074S; Cell Signaling Technology, Inc., Danvers, MA, USA) and anti-goat $\operatorname{IgG}\left(1 \mathrm{~h}\right.$ at $25^{\circ} \mathrm{C} ; 1: 5,000$; cat. no. sc-2020;
Santa Cruz Biotechnology, Inc.). Specific complexes were visualized with an enhanced chemiluminescence detection system (GE Healthcare Life Sciences, Little Chalfont, UK) as described previously (23).

Proteomic analysis. To comprehensively investigate metabolic changes in BC cells treated with salirasib, proteomic analysis was performed using iMPAQT (19). Proteins with downregulated expression were detected in salirasib-treated BC cells compared with untreated cells (fold change $<0.5$ ) and proteins that were common to both T24 and BOY were identified. The proteins were then categorized into Kyoto Encyclopedia of Genes and Genomes (KEGG) pathways through GeneCodis analysis (genecodis.cnb.csic.es).

In vivo tumor xenograft model. To investigate in vivo effects of salirasib, a mixture containing $100 \mu 1$ BOY cells $\left(5 \times 10^{6}\right)$ and $100 \mu 1$ Matrigel Matrix (Corning Incorporated, Corning, NY, USA) was injected subcutaneously into one side flank of 9 female nude mice (BALB/c nu/nu; 8 weeks old; 16-19 g). The mice were randomly separated into salirasib-treated $(n=5)$ and control $(n=4)$ groups. Each breeding room was kept at a temperature of $23 \pm 1^{\circ} \mathrm{C}$ and a humidity of $40-70 \%$. The light/dark cycle was set to $12 \mathrm{~h}$. Food and water was placed to be accessible from each cage. From the day following tumor implantation, salirasib $(0.4 \mathrm{mg} / \mathrm{mouse}$, i.p., daily) and control vehicle ( $0.5 \%$ ethanol, $100 \mu \mathrm{l} /$ mouse, i.p., daily) treatment were administered for 25 days. Tumor sizes were measured twice weekly and tumor volumes were calculated as follows: Tumor volume $=[$ (long axis length in millimeters/2) $\mathrm{x}$ (short axis length $\left./ 2)^{2} \times \pi \times 4\right] / 3$. All animal experiments were performed in accordance with institutional guidelines and were approved by the animal care review board of Kagoshima University (Kagoshima, Japan).

Statistical analysis. Data are presented as the mean \pm standard deviation at least three independent experiments. The relationships between two groups were analyzed using Mann-Whitney $\mathrm{U}$ tests. The relationships between three or more variables and numerical values were analyzed using Bonferroni-adjusted Mann-Whitney U tests. All analyses were performed using Expert StatView software, version 5.0 (SAS Institute, Inc., Cary, NC, USA). $\mathrm{P}<0.05$ was considered to indicate a statistically significant difference.

\section{Results}

Expression levels of HRAS in BC and BC cell lines. The expression levels of $H R A S$ were evaluated using TCGA data from BC samples $(\mathrm{n}=407)$ and normal samples $(\mathrm{n}=19)$. HRAS expression levels were significantly upregulated in tumor tissues compared with those in normal bladder epithelia (tumor, 10.314 \pm 0.813 ; normal, $9.707 \pm 0.826 ; \mathrm{P}=0.0024$, Mann-Whitney $\mathrm{U}$ tests; Fig. 1A). Furthermore, HRAS expression was significantly upregulated in patients with BC with mutant HRAS compared with patients with wild-type HRAS (mutant HRAS, 11.277 \pm 0.805 ; wild-type HRAS, 10.267 $\pm 0.788 ; \mathrm{P}<0.0001$, Mann-Whitney U tests) (Fig. 1B). HRAS mRNA expression was also significantly upregulated in BC cell lines compared to patients with normal bladder tissues (T24, 5.960 \pm 0.344 , 

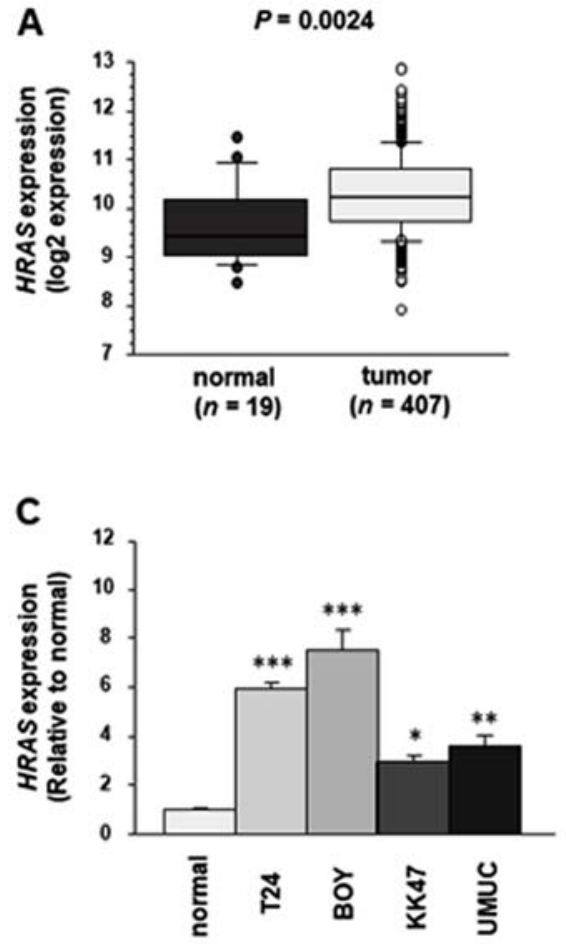

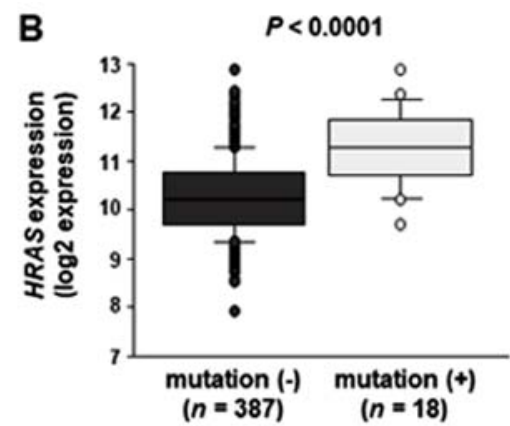

D

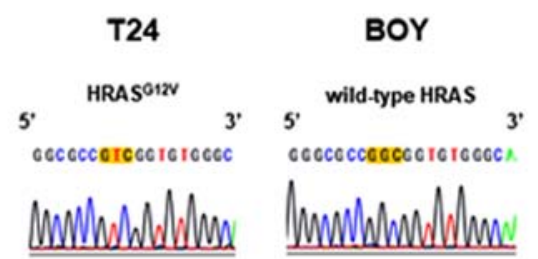

Figure 1. Expression levels of $H R A S$ in BC cell lines and clinical BC samples. Significant upregulation of $H R A S$ expression levels in reverse transcriptionquantitative polymerase chain reaction in (A) BC tumor samples compared with those of normal bladder samples ( $\mathrm{P}=0.0024$; data analyzed by Mann-Whitney $\mathrm{U}$ test are presented as the boxplots) and (B) BC samples with mutant $H R A S$ compared with patients with wild-type $H R A S$ ( $\mathrm{P}<0.0001$, data analyzed by Mann-Whitney U test are presented as the boxplots) and (C) BC cell lines compared with normal bladder tissues ( $\mathrm{P}=0.0176,{ }^{* *} \mathrm{P}=0.0034,{ }^{* * * *} \mathrm{P}<0.0001 \mathrm{vs}$. normal; data analyzed by Bonferroni-adjusted Mann-Whitney test are presented as the mean \pm standard deviation from three independent experiments). (D) Difference in HRAS mutation status among BC cell lines. Sequencing revealed that T24 had HRAS ${ }^{\mathrm{G} 12 \mathrm{~V}}$ (substitution of glycine by valine at codon 12 in $H R A S$ ) and BOY had wild-type HRAS. BC, bladder cancer; HRAS, HRAS proto-oncogene GTPase.

$\mathrm{P}<0.0001 ; \mathrm{BOY}, 7.528 \pm 1.506, \mathrm{P}<0.0001 ; \mathrm{KK} 47,2.934 \pm 0.464$ $\mathrm{P}=0.0176 ; \mathrm{UMUC}, 3.561 \pm 0.854, \mathrm{P}=0.0034$; Bonferroni-adjusted Mann-Whitney U tests; Fig. 1C). Sequencing data from TCGA revealed that $\mathrm{T} 24$ cells had $\mathrm{HRAS}^{\mathrm{G} 12 \mathrm{~V}}$ (the substitution of glycine by valine at codon 12 in HRAS) and BOY cells had wild-type HRAS (Fig. 1D).

Effects of HRAS knockdown on cell proliferation, migration, and invasion of $B C$ cell lines. To investigate the functional role of HRAS in BC cells, loss-of-function studies were performed using T24 and BOY BC cells transfected with three si-HRAS constructs (si-HRAS-1, si-HRAS-2 and si-HRAS-3). RT-qPCR analysis and western blot analysis indicated that these siRNAs effectively downregulated HRAS mRNA and protein expression in both cell lines (Fig. 2A). XTT assays demonstrated that cell proliferation was inhibited in si-HRAS transfectants compared with mock or siRNA-control transfectants (T24, mock 1.0 \pm 0.047 , control 1.0 \pm 0.015 , si-HRAS-1 $0.701 \pm 0.015$, si-HRAS-2 0.615 \pm 0.011 , si-HRAS-3 0.599 \pm 0.024 ; BOY, mock $1.0 \pm 0.024$, control $0.996 \pm 0.087$, si-HRAS-1 $0.585 \pm 0.030$, si-HRAS-2 0.499 \pm 0.020 , si-HRAS-3 0.508 \pm 0.016 ; each $\mathrm{P}<0.0001$, Bonferroni-adjusted Mann-Whitney test; Fig. 2B). Cell migration activity was also significantly inhibited in si-HRAS transfectants compared with mock or siRNA-control transfectants (T24, mock 1.0 \pm 0.111 , control 1.013 \pm 0.117 , si-HRAS-1 $0.684 \pm 0.198$, si-HRAS-2 0.583 \pm 0.309 , si-HRAS-3 0.462 $\pm 0.348, \mathrm{P}=0.0019$ and $\mathrm{P}<0.0001$ vs. mock; BOY, mock $1.0 \pm 0.186$, control $0.978 \pm 0.080$, si-HRAS-1 0.158 \pm 0.105 , si-HRAS-2 $0.438 \pm 0.130$, si-HRAS-3 $0.448 \pm 0.186$, each $\mathrm{P}<0.0001$ vs. mock, Bonferroni-adjusted
Mann-Whitney test; Fig. 2C), as was cell invasion activity in Matrigel assays (T24, mock $1.0 \pm 0.280$, control $1.443 \pm 0.289$, si-HRAS-1 0.543 \pm 0.113 , si-HRAS-2 0.552 \pm 0.154 , si-HRAS-3 $0.353 \pm 0.074$; BOY, mock $1.0 \pm 0.288$, control $1.309 \pm 0.268$, si-HRAS-1 $0.117 \pm 0.070, s i-H R A S-2 \quad 0.296 \pm 0.121$, si-HRAS-3 $0.142 \pm 0.086$, each $\mathrm{P}<0.0001$, Bonferroni-adjusted MannWhitney test; Fig. 2D).

Effects of salirasib on cell proliferation, migration, and invasion activities in BC cell lines. The effect of salirasib treatment was investigated in T24 and BOY cells. XTT assays demonstrated that $\geq 100 \mu \mathrm{M}$ salirasib significantly reduced T24 and BOY viability compared with untreated cells (each $\mathrm{P}<0.0001$, Bonferroni-adjusted Mann-Whitney test; Fig. 3A). Salirasib treatment significantly reduced T24 and BOY cell migration compared with the mock control (T24, mock $1.0 \pm 0.258$, salirasib $0.498 \pm 0.326, \mathrm{P}=0.0020$; BOY, mock $1.0 \pm 0.470$, salirasib $0.556 \pm 0.289, \mathrm{P}=0.0193$, Mann-Whitney $\mathrm{U}$ tests; Fig. 3B) and invasion activity (T24, mock 1.0 \pm 0.336 , salirasib $0.200 \pm 0.116$; BOY, mock $1.0 \pm 0.477$, salirasib $0.122 \pm 0.125, P=0.0009$, Mann-Whitney U tests; Fig. 3C) relative to untreated cells.

Proteomic analysis in BC cells treated with salirasib. To comprehensively investigate metabolic changes in BC cells treated with salirasib, proteomic analysis of metabolismassociated genes was performed using iMPAQT. The results revealed 58 proteins with downregulated expression (fold change $<0.5$ ) in both T24 and BOY BC cells treated with 
Table I. Metabolic changes in bladder cancer cells treated by salirasib.

\begin{tabular}{|c|c|c|c|c|}
\hline \multirow[b]{2}{*}{ Gene symbol } & \multirow[b]{2}{*}{ Description } & \multicolumn{3}{|c|}{$\begin{array}{l}\text { Expression ratio } \\
\text { (treated/untreated cells) }\end{array}$} \\
\hline & & $\mathrm{T} 24$ & BOY & $\begin{array}{c}\text { Mean of T24 } \\
\text { and BOY }\end{array}$ \\
\hline AHCYL1 & Adenosylhomocysteinase-like 1 & ND & ND & ND \\
\hline AK3 & Adenylate kinase 3 & ND & ND & ND \\
\hline ALDH3A2 & Aldehyde dehydrogenase 3 family, member A2 & ND & ND & ND \\
\hline ALDH9A1 & Aldehyde dehydrogenase 9 family, member A1 & ND & ND & ND \\
\hline ASNS & Asparagine synthetase (glutamine-hydrolyzing) & ND & ND & ND \\
\hline ATP5L & ATP synthase, $\mathrm{H}^{+}$transporting, mitochondrial Fo complex, subunit $\mathrm{G}$ & ND & ND & ND \\
\hline ATP6V1E1 & Atpase, $\mathrm{H}^{+}$transporting, lysosomal, V1 subunit E1 & ND & ND & ND \\
\hline ATP6V1G1 & Atpase, $\mathrm{H}^{+}$transporting, lysosomal, $\mathrm{V} 1$ subunit $\mathrm{G} 1$ & ND & ND & ND \\
\hline DCXR & Dicarbonyl/L-xylulose reductase & ND & ND & ND \\
\hline DERA & Deoxyribose-phosphate aldolase (putative) & ND & ND & ND \\
\hline DLD & Dihydrolipoamide dehydrogenase & ND & ND & ND \\
\hline G6PD & Glucose-6-phosphate dehydrogenase & ND & ND & ND \\
\hline GBA & Glucosidase $\beta$, acid & ND & ND & ND \\
\hline GMPPA & GDP-mannose pyrophosphorylase A & ND & ND & ND \\
\hline GMPR2 & Guanosine monophosphate reductase 2 & ND & ND & ND \\
\hline GNPDA1 & Glucosamine-6-phosphate deaminase 1 & ND & ND & ND \\
\hline HSD17B12 & Hydroxysteroid (17- $\beta$ ) dehydrogenase 12 & ND & ND & ND \\
\hline IDI1 & Isopentenyl-diphosphate delta isomerase 1 & ND & ND & ND \\
\hline IVD & Isovaleryl-coa dehydrogenase & ND & ND & ND \\
\hline MPST & Mercaptopyruvate sulfurtransferase & ND & ND & ND \\
\hline MTMR1 & Myotubularin related protein 1 & ND & ND & ND \\
\hline NDUFS8 & $\begin{array}{l}\text { NADH dehydrogenase (ubiquinone) } \\
\text { Fe-S protein } 8,2 \text { (NADH-coenzyme Q reductase) }\end{array}$ & ND & ND & ND \\
\hline NUDT9 & Nudix (nucleoside diphosphate linked moiety X)-type motif 9 & ND & ND & ND \\
\hline PAFAH1B3 & Platelet-activating factor acetylhydrolase $1 b$, catalytic subunit 3 & ND & ND & ND \\
\hline PANK4 & Pantothenate kinase 4 & ND & ND & ND \\
\hline PFKM & Phosphofructokinase, muscle & ND & ND & ND \\
\hline PGD & Phosphogluconate dehydrogenase & ND & ND & ND \\
\hline PGM2 & Phosphoglucomutase 2 & ND & ND & ND \\
\hline PLOD3 & Procollagen-lysine, 2-oxoglutarate 5-dioxygenase 3 & ND & ND & ND \\
\hline PMVK & Phosphomevalonate kinase & ND & ND & ND \\
\hline PRIM1 & Primase, DNA, polypeptide 1 & ND & ND & ND \\
\hline $\mathrm{SCP} 2$ & Sterol carrier protein 2 & ND & ND & ND \\
\hline UQCRB & Ubiquinol-cytochrome $\mathrm{c}$ reductase binding protein & ND & ND & ND \\
\hline GAPDH & Glyceraldehyde-3-phosphate dehydrogenase & 0.068 & 0.113 & 0.091 \\
\hline GOT1 & $\begin{array}{l}\text { Glutamic-oxaloacetic transaminase } 1 \text {, soluble } \\
\text { (aspartate aminotransferase } 1 \text { ) }\end{array}$ & ND & 0.242 & 0.121 \\
\hline BCAT1 & Branched chain amino-acid transaminase 1 , cytosolic & 0.247 & ND & 0.123 \\
\hline AASDHPPT & $\begin{array}{l}\text { Aminoadipate-semialdehyde } \\
\text { dehydrogenase-phosphopantetheinyl transferase }\end{array}$ & ND & 0.256 & 0.128 \\
\hline UAP1 & UDP-N-acteylglucosamine pyrophosphorylase 1 & 0.107 & 0.212 & 0.16 \\
\hline PGM3 & Phosphoglucomutase 3 & ND & 0.393 & 0.197 \\
\hline PAFAH1B2 & Platelet-activating factor acetylhydrolase $1 b$, catalytic subunit 2 & ND & 0.405 & 0.203 \\
\hline BLVRB & Biliverdin reductase B (flavin reductase (NADPH)) & ND & 0.407 & 0.204 \\
\hline NDUFS1 & $\begin{array}{l}\text { NADH dehydrogenase (ubiquinone) Fe-S protein } 1 \text {, } \\
7 \text { (NADH-coenzyme Q reductase) }\end{array}$ & ND & 0.492 & 0.246 \\
\hline DLST & $\begin{array}{l}\text { Dihydrolipoamide S-succinyltransferase (E2 component of } \\
\text { 2-oxo-glutarate complex) }\end{array}$ & 0.293 & 0.201 & 0.247 \\
\hline PHGDH & Phosphoglycerate dehydrogenase & 0.224 & 0.284 & 0.254 \\
\hline
\end{tabular}



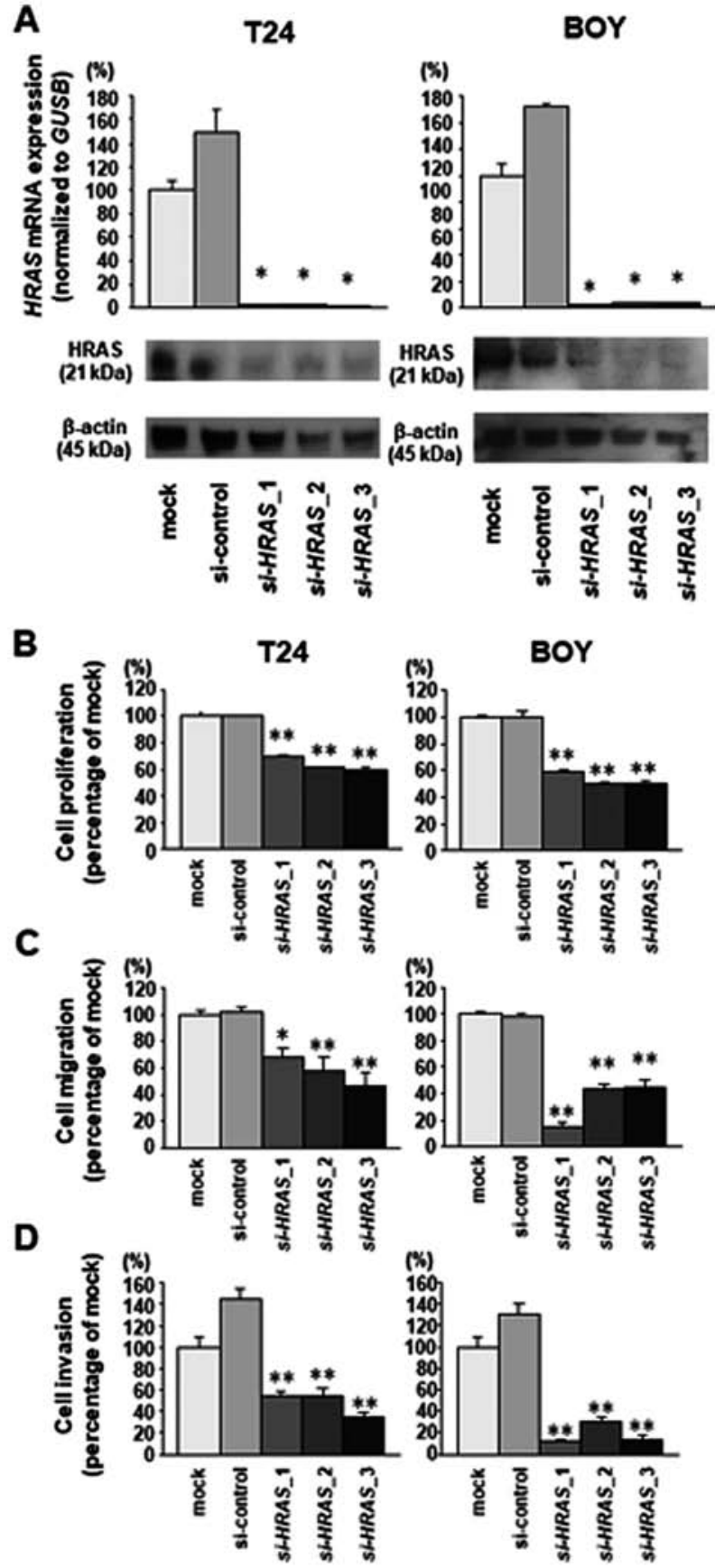

Figure 2. Effects of siRNA-induced HRAS knockdown on bladder cancer cell lines. (A) Transfection of T24 and BOY cells with si-HRAS show significant ("P<0.0001 vs. mock, Bonferroni-adjusted Mann-Whitney test) downregulation of HRAS mRNA and protein expression by reverse transcription-quantitative polymerase chain reaction and western blotting, respectively. Glucuronidase $\beta$ and $\beta$-actin were used as internal and loading controls, respectively. siRNA-induced HRAS knockdown inhibited cell proliferation, migration, and invasion as determined by (B) XTT, (C) wound healing and (D) Matrigel invasion assays. ( $\mathrm{P}=0.002$ and ${ }^{* *} \mathrm{P}<0.0001$ vs. mock, Bonferroni-adjusted Mann-Whitney test). All data are presented as the mean \pm standard deviation. All results represent reproducible data from at least three independent experiments. si, small interfering RNA.

salirasib compared to untreated cells (Table I). GeneCodis analysis to categorize the proteins into KEGG pathways demonstrated that these proteins were included in 50 pathways that were significantly enriched following salirasib treatment (listed in descending order of corrected P-values in Table II; Fig. 4). 'Oxidative phosphorylation', 'pyrimidine metabolism', 'glycolysis/gluconeogenesis', 'pentose phosphate pathway', 'cysteine and methionine metabolism', 'glutathione metabolism', and 'purine metabolism' were significantly downregulated pathways in BC cells treated with salirasib. However, target genes of the RAS effector HIF-1 $\alpha$, including hexokinase 2, phosphoglycerate kinase 1, pyruvate kinase, muscle (PKM)1, PKM2 and lactate dehydrogenase A, showed only modest downregulation (fold change $>0.5$ in T24 and BOY cells) (Table III) (24-26). Furthermore, RT-qPCR analysis and western blot analysis indicated that expression of HIF- $1 \alpha$ was not downregulated in salirasib-treated BC cells (Fig. 5) $(5,27)$.

Xenograft model study to investigate the in vivo effects of salirasib. To investigate the in vivo effects of salirasib, either salirasib or control vehicle was i.p. injected daily into BC xenograft mice from one day after tumor implantation. There was no difference in tumor growth between the salirasibtreated group $\left(\mathrm{n}=5,545.9 \pm 187.4 \mathrm{~mm}^{3}\right)$ and control group $(\mathrm{n}=4$, $511.2 \pm 165.6 \mathrm{~mm}^{3}$ ) (Fig. 6) on day 27 after tumor implantation.

\section{Discussion}

HRAS was the first human oncogene reported in the T24 BC cell line in 1982 (28). Several reports have indicated that $H R A S$ mutations critically influence tumorigenesis and development of BC $(8,29-33)$. Haliassos et al (29) detected HRAS codon 12 point mutations in $66 \%$ of $\mathrm{BC}$ specimens and the mutant HRAS allele in the urine of $47 \%$ of patients with BC, Pandith et al (33) reported that HRAS single nucleotide polymorphism increases $\mathrm{BC}$ risk, and rare allele is a predictive marker of advanced bladder tumors. However, RAS had been considered to be 'undruggable' because the RAS protein lacked a druggable binding pocket until salirasib was produced. Salirasib inhibits RAS-dependent cell growth by dislodging all isoforms of RAS from the plasma membrane $(11,12)$. The antitumor efficacy of salirasib has been demonstrated in several cell lines and xenograft models (17,34-36). Goldberg et al (34) demonstrated that salirasib induces pancreatic cancer cell death and tumor shrinkage in mice, and that salirasib was efficient and nontoxic for treatment of glioblastoma in a rat model (35). Charette et al (36) reported that salirasib inhibits the growth of hepatocarcinoma cell lines in vitro and in vivo through RAS and mTOR inhibition. Salirasib was evaluated as a single agent in two clinical trials; however, neither produced promising results in patients with KRAS mutation positive lung adenocarcinoma (13) or refractory hematologic malignancies (14). Even though these clinical trials demonstrated the relative safety of salirasib, diarrhea, nausea and fatigue were the most common toxicities, and there were no grade 4 or 5 drug-associated adverse events or dose-limiting toxicity. On the other hand, results of a combination study of salirasib with gemcitabine to treat pancreatic adenocarcinoma were sufficiently encouraging to warrant further investigation $(15,16)$.

Although the efficacy of salirasib has been reported for several types of cancers, to the best of our knowledge, this is the first report concerning the effect of salirasib in BC. Two $\mathrm{BC}$ cell lines were used to evaluate the ability of salirasib to target HRAS. T24 carries the HRAS ${ }^{\mathrm{G} 12 \mathrm{~V}}$ mutation (substitution of glycine by valine at codon 12 of $H R A S$ ) and sequencing data demonstrated that BOY cells have wild-type HRAS. 
Table I. Continued.

\begin{tabular}{|c|c|c|c|c|}
\hline \multirow[b]{2}{*}{ Gene symbol } & \multirow[b]{2}{*}{ Description } & \multicolumn{3}{|c|}{$\begin{array}{c}\text { Expression ratio } \\
\text { (treated/untreated cells) }\end{array}$} \\
\hline & & $\mathrm{T} 24$ & BOY & $\begin{array}{l}\text { Mean of T24 } \\
\text { and BOY }\end{array}$ \\
\hline HMOX1 & Heme oxygenase (decycling) 1 & 0.165 & 0.378 & 0.271 \\
\hline DUT & Deoxyuridine triphosphatase & 0.223 & 0.369 & 0.296 \\
\hline $\mathrm{AHCY}$ & Adenosylhomocysteinase & 0.297 & 0.315 & 0.306 \\
\hline ATP5A1 & $\begin{array}{l}\text { ATP synthase, } \mathrm{H}^{+} \text {transporting, mitochondrial } \mathrm{F} 1 \\
\text { complex }, \alpha \text { subunit } 1 \text {, cardiac muscle }\end{array}$ & 0.252 & 0.363 & 0.308 \\
\hline SRM & Spermidine synthase & 0.297 & 0.401 & 0.349 \\
\hline RRM1 & Ribonucleotide reductase M1 & 0.347 & 0.36 & 0.353 \\
\hline ACAT1 & Acetyl-coa acetyltransferase 1 & 0.271 & 0.439 & 0.355 \\
\hline ISYNA1 & Inositol-3-phosphate synthase 1 & 0.234 & 0.48 & 0.357 \\
\hline NDUFA4 & NADH dehydrogenase (ubiquinone) $1 \alpha$ subcomplex, 4 & 0.286 & 0.45 & 0.368 \\
\hline RRM2B & Ribonucleotide reductase M2 B (TP53 inducible) & 0.373 & 0.435 & 0.404 \\
\hline NUDT2 & Nudix (nucleoside diphosphate linked moiety X)-type motif 2 & 0.443 & 0.383 & 0.413 \\
\hline UQCRQ & Ubiquinol-cytochrome c reductase, complex III subunit VII & 0.414 & 0.451 & 0.432 \\
\hline CMPK1 & Cytidine monophosphate (UMP-CMP) kinase 1 , cytosolic & 0.462 & 0.443 & 0.452 \\
\hline ATP6V1B2 & Atpase, $\mathrm{H}^{+}$transporting, lysosomal, $\mathrm{V} 1$ subunit $\mathrm{B} 2$ & 0.498 & 0.479 & 0.489 \\
\hline
\end{tabular}

ND, not detectable (set as 0$)$.

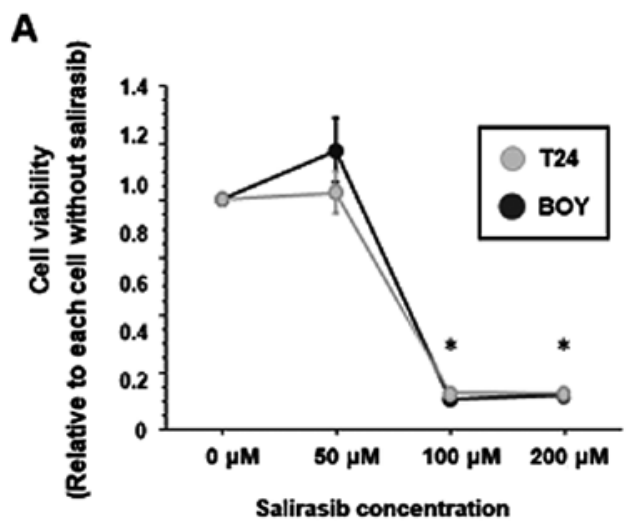

B
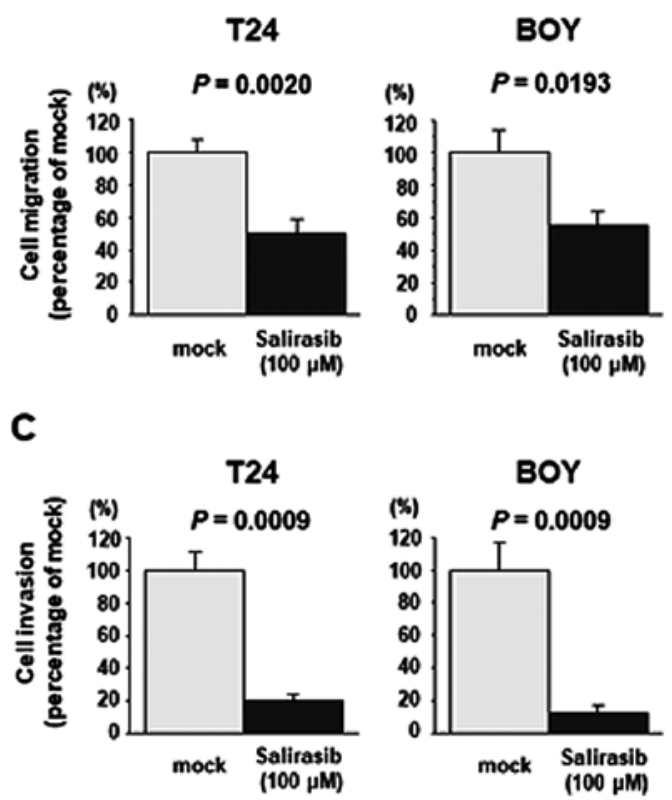

Figure 3. Salirasib inhibition of cell proliferation, migration, and invasion. Compared with vehicle-treated cells, treatment of T24 and BOY cells with 100 and $200 \mu \mathrm{M}$ salirasib inhibited (A) cell proliferation in XTT assays (each "P<0.0001, Bonferroni-adjusted Mann-Whitney U test). Treatment of of T24 and BOY cells with salirasib $(100 \mu \mathrm{M})$ inhibited (B) cell migration in would healing assays ( $\mathrm{P}=0.002$ and $\mathrm{P}=0.0194$, respectively, Mann-Whitney $\mathrm{U}$ test) and (C) cell invasion in Matrigel invasion assays (each $\mathrm{P}=0.0009$, Mann-Whitney $\mathrm{U}$ test). Data are presented as the mean \pm standard deviation. All results represent reproducible data from at least three independent experiments.

siRNA-induced HRAS knockdown and salirasib inhibition of HRAS exerted tumor suppressive effects regardless of HRAS mutational status in vitro, which was consistent with several previously published results demonstrating a lack of correlation between RAS mutational status and response to RAS-targeting therapy $(37,38)$. However, salirasib still required relatively high concentrations to achieve a tumor-suppressive effect in vitro, and exhibited no tumor-suppressive effects in vivo. 


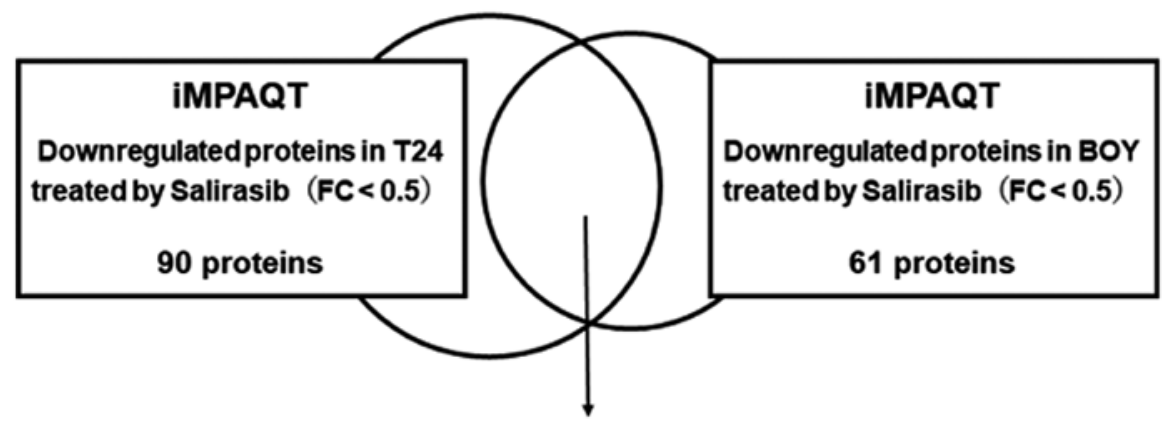

58 common downregulated proteins

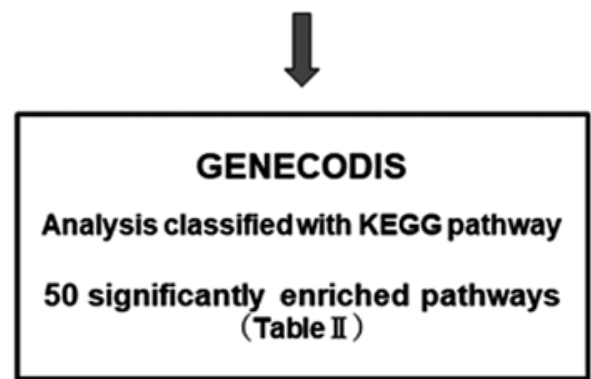

Figure 4. Strategy to identify metabolic pathways downregulated in salirasib-treated BC cells. Proteomic analysis using iMPAQT detected 58 proteins downregulated in both $\mathrm{T} 24$ and BOY BC cells treated with salirasib $(\mathrm{FC}<0.5)$. Categorization of these proteins into KEGG pathways using GeneCodis analysis showed that 50 pathways were downregulated following salirasib treatment of BC cells. BC, breast cancer; iMPAQT, in vitro proteome-assisted multiple reaction monitoring for protein absolute quantification; FC, fold change; KEGG, Kyoto Encyclopedia of Genes and Genomes.
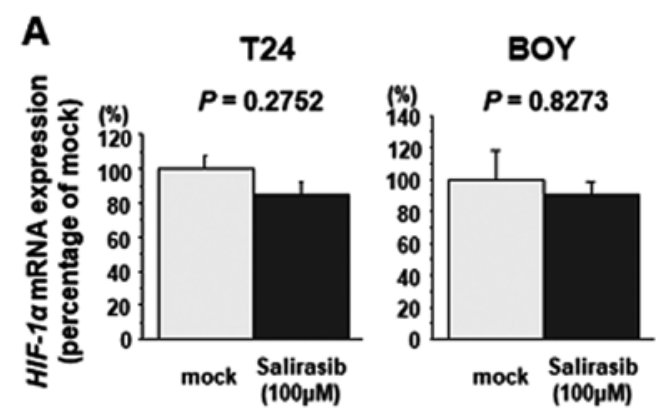

B

T24
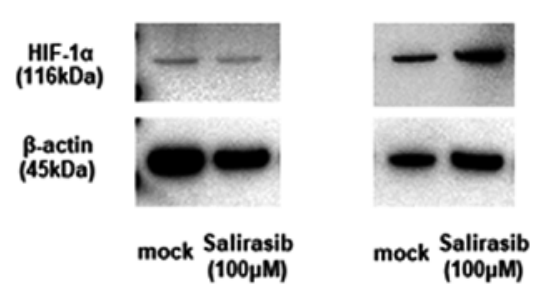

Figure 5. Effect of salirasib on HIF-1 $\alpha$. (A) Reverse transcription-quantitative polymerase chain reaction analysis and (B) western blot analysis indicated that HIF-1 $\alpha$ mRNA and protein expression were not effectively downregulated in salirasib-treated bladder cancer cells. Data are presented as the mean \pm standard deviation. All results represent reproducible data from at least three independent experiments. HIF-1 $\alpha$, hypoxia inducible factor- $1 \alpha$.

It had been reported that oncogenic RAS predominantly affects the metabolic reprogramming of cancer cells through the upregulation of HIF-1 $\alpha$, one of target genes of RAS (5). Although salirasib is known to competitively block intracellular signaling via the RAS cascade, there are no reports concerning comprehensive metabolomic analysis of salirasib mechanisms. In the current study, proteomic analysis was performed using

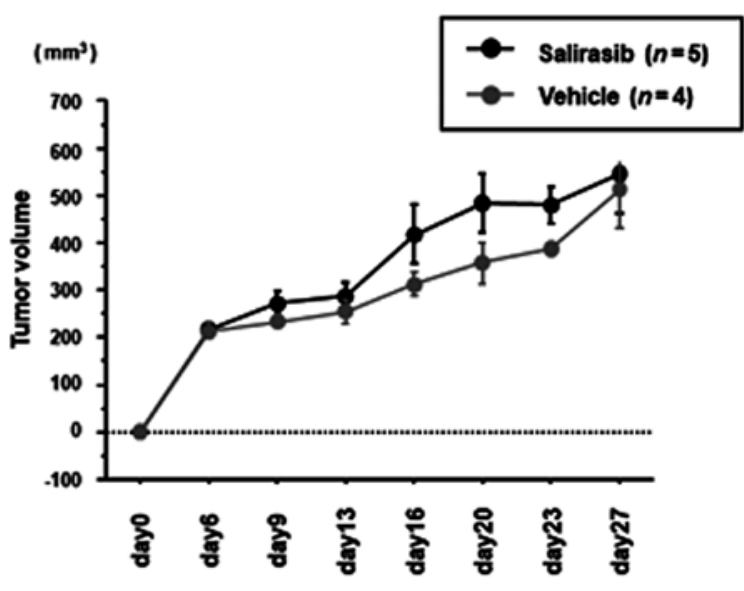

Figure 6. In vivo effects of salirasib in xenograft models. Salirasib and control vehicle were intraperitoneally injected daily into BOY cell bladder cancer xenograft mice for 25 days from the day following tumor implantation. There was no difference in tumor size between the salirasib-treated group $(n=5)$ and control group $(n=4)$ at any indicated time point after tumor implantation. The statistical analysis was performed by Mann-Whitney U test. Data are presented as the mean \pm standard deviation. The result represents reproducible data from at least three independent experiments.

iMPAQT to investigate metabolic changes in salirasib-treated $\mathrm{BC}$ cells. Pathway analysis using the proteomic data indicated that 50 pathways were significantly downregulated following salirasib treatment of BC cells, including 'Oxidative phosphorylation', 'Glycolysis/gluconeogenesis', and 'Pentose phosphate pathway'. However, proteomic analysis showed that the expression of proteins downstream of HIF-1 $\alpha$ were not significantly downregulated. Furthermore, HIF-1 $\alpha$ expression was not efficiently suppressed in salirasib-treated BC cells, although it was previously reported that salirasib suppressed HIF-1 $\alpha$ expression 
Table II. Downregulated KEGG pathways in bladder cancer cells treated by salirasib.

\begin{tabular}{|c|c|c|c|c|}
\hline $\begin{array}{l}\text { KEGG } \\
\text { ID }\end{array}$ & Annotations & $\begin{array}{l}\text { Number } \\
\text { of genes }\end{array}$ & $\begin{array}{l}\text { Corrected } \\
\text { P-value }\end{array}$ & Genes \\
\hline 00190 & Oxidative phosphorylation & 10 & $1.22 \times 10^{-12}$ & $\begin{array}{l}\text { ATP5A1, ATP6V1G1, NDUFS8, } \\
\text { ATP5L, ATP6V1E1, NDUFA4, NDUFS1, } \\
\text { UQCRB, ATP6V1B2, UQCRQ }\end{array}$ \\
\hline 00280 & Valine, leucine and isoleucine degradation & 6 & $3.79 \times 10^{-9}$ & $\begin{array}{l}\text { ALDH3A2, DLD, BCAT1, IVD, } \\
\text { ALDH9A1, ACAT1 }\end{array}$ \\
\hline 00240 & Pyrimidine metabolism & 7 & $4.84 \times 10^{-9}$ & $\begin{array}{l}\text { CMPK1, NUDT2, RRM2B, AK3, } \\
\text { RRM1, PRIM1, DUT }\end{array}$ \\
\hline 00010 & Glycolysis/gluconeogenesis & 6 & $1.29 \times 10^{-8}$ & $\begin{array}{l}\text { ALDH3A2, PGM2, DLD, ALDH9A1, } \\
\text { GAPDH, PFKM }\end{array}$ \\
\hline 00030 & Pentose phosphate pathway & 5 & $1.43 \times 10^{-8}$ & PGM2, DERA, G6PD, PGD, PFKM \\
\hline 00270 & Cysteine and methionine metabolism & 5 & $4.39 \times 10^{-8}$ & MPST, AHCY, AHCYL1, SRM, GOT1 \\
\hline 00480 & Glutathione metabolism & 5 & $8.35 \times 10^{-8}$ & RRM2B, G6PD, RRM1, SRM, PGD \\
\hline 00230 & Purine metabolism & 7 & $8.57 \times 10^{-8}$ & $\begin{array}{l}\text { NUDT2, PGM2, GMPR2, RRM2B, RRM1, } \\
\text { NUDT9, PRIM1 }\end{array}$ \\
\hline 05010 & Alzheimer's disease & 7 & $9.31 \times 10^{-8}$ & $\begin{array}{l}\text { ATP5A1, NDUFS8, NDUFA4, NDUFS1, } \\
\text { UQCRB, GAPDH, UQCRQ }\end{array}$ \\
\hline 00520 & $\begin{array}{l}\text { Amino sugar and nucleotide } \\
\text { sugar metabolism }\end{array}$ & 5 & $1.18 \times 10^{-7}$ & PGM2, UAP1, GMPPA, PGM3, GNPDA1 \\
\hline 00310 & Lysine degradation & 5 & $1.19 \times 10^{-7}$ & ALDH3A2, ALDH9A1, PLOD3, DLST, ACAT1 \\
\hline 05012 & Parkinson's disease & 6 & $4.55 \times 10^{-7}$ & $\begin{array}{l}\text { ATP5A1, NDUFS8, NDUFA4, NDUFS1, } \\
\text { UQCRB, UQCRQ }\end{array}$ \\
\hline 05016 & Huntington's disease & 6 & $2.79 \times 10^{-6}$ & $\begin{array}{l}\text { ATP5A1, NDUFS8, NDUFA4, NDUFS1, } \\
\text { UQCRB, UQCRQ }\end{array}$ \\
\hline 00620 & Pyruvate metabolism & 4 & $2.79 \times 10^{-6}$ & ALDH3A2, DLD, ALDH9A1, ACAT1 \\
\hline 00330 & Arginine and proline metabolism & 4 & $8.56 \times 10^{-6}$ & ALDH3A2, ALDH9A1, SRM, GOT1 \\
\hline 00900 & Terpenoid backbone biosynthesis & 3 & $8.57 \times 10^{-6}$ & PMVK, IDI1, ACAT1 \\
\hline 00770 & Pantothenate and CoA biosynthesis & 3 & $1.13 \times 10^{-5}$ & BCAT1, AASDHPPT, PANK4 \\
\hline 00410 & $\beta$-alanine metabolism & 3 & $3.82 \times 10^{-5}$ & ALDH3A2, ALDH9A1, SRM \\
\hline 04966 & Collecting duct acid secretion & 3 & $3.82 \times 10^{-5}$ & ATP6V1G1, ATP6V1E1, ATP6V1B2 \\
\hline 00640 & Propanoate metabolism & 3 & $6.87 \times 10^{-5}$ & ALDH3A2, ALDH9A1, ACAT1 \\
\hline 00051 & Fructose and mannose metabolism & 3 & $9.37 \times 10^{-5}$ & GMPPA, MTMR1, PFKM \\
\hline 00071 & Fatty acid metabolism & 3 & 0.000127 & ALDH3A2, ALDH9A1, ACAT1 \\
\hline 00380 & Tryptophan metabolism & 3 & 0.000127 & ALDH3A2, ALDH9A1, ACAT1 \\
\hline 05110 & Vibrio cholerae infection & 3 & 0.000264 & ATP6V1G1, ATP6V1E1, ATP6V1B2 \\
\hline 05120 & $\begin{array}{l}\text { Epithelial cell signaling in } \\
\text { Helicobacter pylori infection }\end{array}$ & 3 & 0.000509 & ATP6V1G1, ATP6V1E1, ATP6V1B2 \\
\hline 05323 & Rheumatoid arthritis & 3 & 0.000953 & ATP6V1G1, ATP6V1E1, ATP6V1B2 \\
\hline 00053 & Ascorbate and aldarate metabolism & 2 & 0.002054 & ALDH3A2, ALDH9A1 \\
\hline 00052 & Galactose metabolism & 2 & 0.002137 & PGM2, PFKM \\
\hline 00340 & Histidine metabolism & 2 & 0.002381 & ALDH3A2, ALDH9A1 \\
\hline 00020 & Citrate cycle (TCA cycle) & 2 & 0.002464 & DLD, DLST \\
\hline 00040 & Pentose and glucuronate interconversions & 2 & 0.002546 & ALDH3A2, DCXR \\
\hline 00250 & Alanine, aspartate and glutamate metabolism & 2 & 0.002548 & ASNS, GOT1 \\
\hline 00260 & Glycine, serine and threonine metabolism & 2 & 0.002548 & DLD, PHGDH \\
\hline 00565 & Ether lipid metabolism & 2 & 0.002791 & PAFAH1B3, PAFAH1B2 \\
\hline 04145 & Phagosome & 3 & 0.002924 & ATP6V1G1, ATP6V1E1, ATP6V1B2 \\
\hline 00860 & Porphyrin and chlorophyll metabolism & 2 & 0.004011 & HMOX1, BLVRB \\
\hline 00561 & Glycerolipid metabolism & 2 & 0.004873 & ALDH3A2, ALDH9A1 \\
\hline 04260 & Cardiac muscle contraction & 2 & 0.011811 & UQCRB, UQCRQ \\
\hline
\end{tabular}


Table II. Continued.

\begin{tabular}{|c|c|c|c|c|}
\hline $\begin{array}{l}\text { KEGG } \\
\text { ID }\end{array}$ & Annotations & $\begin{array}{l}\text { Number } \\
\text { of genes }\end{array}$ & $\begin{array}{l}\text { Corrected } \\
\text { P-value }\end{array}$ & Genes \\
\hline 04146 & Peroxisome & 2 & 0.011811 & PMVK, SCP2 \\
\hline 00400 & $\begin{array}{l}\text { Phenylalanine, tyrosine and } \\
\text { tryptophan biosynthesis }\end{array}$ & 1 & 0.013097 & GOT1 \\
\hline 00072 & Synthesis and degradation of ketone bodies & 1 & 0.022922 & ACAT1 \\
\hline 00290 & Valine, leucine and isoleucine biosynthesis & 1 & 0.024264 & BCAT1 \\
\hline 04122 & Sulfur relay system & 1 & 0.024264 & MPST \\
\hline 00740 & Riboflavin metabolism & 1 & 0.026063 & BLVRB \\
\hline 00360 & Phenylalanine metabolism & 1 & 0.036111 & GOT1 \\
\hline 00120 & Primary bile acid biosynthesis & 1 & 0.036111 & $\mathrm{SCP} 2$ \\
\hline 00511 & Other glycan degradation & 1 & 0.03752 & GBA \\
\hline 00630 & Glyoxylate and dicarboxylate metabolism & 1 & 0.038867 & ACAT1 \\
\hline 01040 & Biosynthesis of unsaturated fatty acids & 1 & 0.044309 & HSD17B12 \\
\hline 00910 & Nitrogen metabolism & 1 & 0.04748 & ASNS \\
\hline
\end{tabular}

KEGG, Kyoto Encyclopedia of Genes and Genomes.

Table III. Effects of salirasib downstream of hypoxia inducible factor- $1 \alpha$.

\begin{tabular}{|c|c|c|c|c|}
\hline Name & Description & T24 fold change & BOY fold change & $\begin{array}{c}\text { Mean of T24 } \\
\text { and BOY }\end{array}$ \\
\hline PKM2 & Pyruvate kinase, muscle 2 & 1.369 & 1.194 & 1.281 \\
\hline LDHA & Lactate dehydrogenase A & 0.918 & 1.005 & 0.961 \\
\hline PKM1 & Pyruvate kinase, muscle 1 & 0.900 & 1.044 & 0.972 \\
\hline PGK1 & Phosphoglycerate kinase 1 & 0.857 & 1.192 & 1.025 \\
\hline HK2 & Hexokinase 2 & 0.735 & 0.697 & 0.716 \\
\hline ENO1 & Enolase $1,(\alpha)$ & 0.453 & 0.587 & 0.520 \\
\hline GAPDH & Glyceraldehyde-3-phosphate dehydrogenase & 0.068 & 0.113 & 0.091 \\
\hline
\end{tabular}

in other type of cancer cells (27). Therefore, downregulation of RAS target genes in in vitro assays involving BC cell lines may require a high concentration of salirasib, and this need for high concentrations was responsible for the lack of tumor suppressive effects observed in the BC xenograft mouse model. In this study, whether factors downstream of HIF-1 $\alpha$ were insufficiently downregulated in the tumors from animal experiments was not analyzed by iMPAQT, because iMPAQT is so sensitive that contamination of surrounding tissues adjacent to tumor tissue may make the interpretation of the results difficult. However, these analyses of micro-dissected in vivo samples will be performed in the future. Recently, a novel RAS inhibitor developed using an innovative approach was reported to inhibit tumor growth in animal models of RAS-dependent cancers at low concentrations (39). This novel RAS inhibitor was computationally designed to target multiple sites on RAS proteins, thus enabling sufficient affinity and selectivity for pharmacological RAS inhibition. This new inhibitor may provide successful targeting of RAS in the near future. Therefore, clinical trials with these inhibitors or next-generation RAS inhibitors are required to improve cancer treatment options in the near future.
In conclusion, the current study demonstrated that salirasib and siRNA-induced HRAS knockdown produced tumor suppressive effects regardless of HRAS mutational status in $\mathrm{BC}$ cell lines. However, high concentrations of salirasib were required to inhibit cell proliferation, migration and invasion activity in vitro, and the same high concentrations exhibited no tumor suppressive effects in vivo. Proteomic analysis revealed that several metabolic pathways were significantly downregulated in BC cells treated with salirasib. However, salirasib treatment of BC cells did not significantly affect expression of genes targeted by HIF- $1 \alpha$ in BC cells. These findings provide novel information concerning the mechanism of salirasib effects, and suggest that novel therapeutics involving combination therapies of salirasib with other inhibitors, or the newly-identified novel RAS inhibitor, may be effective for treating $\mathrm{BC}$ and other types of cancer.

\section{Acknowledgements}

The authors wish to thank Ms. Mutsumi Miyazaki,(Department of Urology, Graduate School of Medical and Dental Sciences, 
Kagoshima University, Kagoshima, Japan) for laboratory assistance.

\section{Funding}

This study was supported by JSPS Grants-in-Aid for Scientific Research (grant nos. 16H05464, 17H04332 and 16K11015).

\section{Availability of data and materials}

The analyzed datasets generated during the study are available from the corresponding author on reasonable request.

\section{Authors' contributions}

HY conceived and designed the experiments. SS, HY, KM, MY, TS and YO performed the experiments. SS, HE, HY and $\mathrm{KM}$ performed the validation and formal analysis. SS and $\mathrm{KM}$ wrote the manuscript. $\mathrm{HE}, \mathrm{HY}$ and $\mathrm{MN}$ interpreted experimental data for the work, and reviewed and revised the manuscript. HE, HY and MN acquired funding. All authors have read and approved the final manuscript.

\section{Ethics approval and consent to participate}

Not applicable.

\section{Patient consent for publication}

Not applicable.

\section{Competing interests}

The authors declare that they have no competing interests.

\section{References}

1. Ferlay J, Steliarova-Foucher E, Lortet-Tieulent J, Rosso S, Coebergh JW, Comber H, Forman D and Bray F: Cancer incidence and mortality patterns in Europe: Estimates for 40 countries in 2012. Eur J Cancer 49: 1374-1403, 2013.

2. Torre LA, Bray F, Siegel RL, Ferlay J, Lortet-Tieulent J and Jemal A: Global cancer statistics, 2012. CA Cancer J Clin 65: 87-108, 2015.

3. Abdollah F, Gandaglia G, Thuret R, Schmitges J, Tian Z, Jeldres C, Passoni NM, Briganti A, Shariat SF, Perrotte P, et al: Incidence, survival and mortality rates of stage-specific bladder cancer in United States: A trend analysis. Cancer Epidemiol 37: 219-225, 2013.

4. Advanced Bladder Cancer Meta-analysis Collaboration: Neoadjuvant chemotherapy in invasive bladder cancer: A systematic review and meta-analysis. Lancet 361: 1927-1934, 2003.

5. Pylayeva-Gupta Y, Grabocka E and Bar-Sagi D: RAS oncogenes: Weaving a tumorigenic web. Nat Rev Cancer 11: 761-774, 2011.

6. Karnoub AE and Weinberg RA: Ras oncogenes: Split personalities. Nat Rev Mol Cell Biol 9: 517-531, 2008

7. Ding L, Getz G, Wheeler DA, Mardis ER, McLellan MD, Cibulskis K, Sougnez C, Greulich H, Muzny DM, Morgan MB, et al: Somatic mutations affect key pathways in lung adenocarcinoma. Nature 455: 1069-1075, 2008

8. Kiaris H and Spandidos D: Mutations of ras genes in human tumors (Review). Int J Oncol 7: 413-421, 1995.

9. Baines AT, Xu D and Der CJ: Inhibition of Ras for cancer treatment: The search continues. Future Med Chem 3: 1787-1808, 2011.

10. Cox AD, Fesik SW, Kimmelman AC, Luo J and Der CJ: Drugging the undruggable RAS: Mission possible? Nat Rev Drug Discov 13: $828-851,2014$
11. Elad G, Paz A, Haklai R, Marciano D, Cox A and Kloog Y: Targeting of K-Ras 4B by S-trans,trans-farnesyl thiosalicylic acid. Biochim Biophys Acta 1452: 228-242, 1999.

12. Weisz B, Giehl K, Gana-Weisz M, Egozi Y, Ben-Baruch G, Marciano D, Gierschik P and Kloog Y: A new functional Ras antagonist inhibits human pancreatic tumor growth in nude mice. Oncogene 18: 2579-2588, 1999.

13. Riely GJ, Johnson ML, Medina C, Rizvi NA, Miller VA, Kris MG, Pietanza MC, Azzoli CG, Krug LM, Pao W, et al: A phase II trial of Salirasib in patients with lung adenocarcinomas with KRAS mutations. J Thorac Oncol 6: 1435-1437, 2011.

14. Badar T, Cortes JE, Ravandi F, O'Brien S, Verstovsek S, Garcia-Manero G, Kantarjian H and Borthakur G: Phase I study of S-trans, trans-farnesylthiosalicylic acid (salirasib), a novel oral RAS inhibitor in patients with refractory hematologic malignancies. Clin Lymphoma Myeloma Leuk 15: 433-438.e2, 2015.

15. Bustinza-Linares E, Kurzrock R and Tsimberidou AM: Salirasib in the treatment of pancreatic cancer. Future Oncol 6: 885-891, 2010.

16. Laheru D, Shah P, Rajeshkumar NV, McAllister F, Taylor G, Goldsweig H, Le DT, Donehower R, Jimeno A, Linden S, et al: Integrated preclinical and clinical development of S-trans, transFarnesylthiosalicylic Acid (FTS, Salirasib) in pancreatic cancer. Invest New Drugs 30: 2391-2399, 2012.

17. Makovski V, Haklai R and Kloog Y: Farnesylthiosalicylic acid (salirasib) inhibits Rheb in TSC2-null ELT3 cells: A potential treatment for lymphangioleiomyomatosis. Int J Cancer 130: 1420-1429, 2012

18. Zundelevich A, Elad-Sfadia G, Haklai R and Kloog Y: Suppression of lung cancer tumor growth in a nude mouse model by the Ras inhibitor salirasib (farnesylthiosalicylic acid). Mol Cancer Ther 6: 1765-1773, 2007.

19. Matsumoto M, Matsuzaki F, Oshikawa K, Goshima N, Mori M, Kawamura Y, Ogawa K, Fukuda E, Nakatsumi H, Natsume T, et al: A large-scale targeted proteomics assay resource based on an in vitro human proteome. Nat Methods 14: 251-258, 2017.

20. Li B and Dewey CN: RSEM: Accurate transcript quantification from RNA-Seq data with or without a reference genome. BMC Bioinformatics 12: 323, 2011

21. Livak KJ and Schmittgen TD: Analysis of relative gene expression data using real-time quantitative PCR and the 2(-Delta Delta $\mathrm{C}(\mathrm{T})$ ) method. Methods 25: 402-408, 2001.

22. Ichimi T, Enokida H, Okuno Y, Kunimoto R, Chiyomaru T, Kawamoto K, Kawahara K, Toki K, Kawakami K, Nishiyama K, et al: Identification of novel microRNA targets based on microRNA signatures in bladder cancer. Int J Cancer 125: 345-352, 2009.

23. Yoshino H, Chiyomaru T, Enokida H, Kawakami K, Tatarano S, Nishiyama K, Nohata N, Seki N and Nakagawa M: The tumoursuppressive function of miR-1 and miR-133a targeting TAGLN2 in bladder cancer. Br J Cancer 104: 808-818, 2011.

24. Masoud GN and Li W: HIF-1 $\alpha$ pathway: Role, regulation and intervention for cancer therapy. Acta Pharm Sin B 5: 378-389, 2015.

25. Qing G, Skuli N, Mayes PA, Pawel B, Martinez D, Maris JM and Simon MC: Combinatorial regulation of neuroblastoma tumor progression by N-Myc and hypoxia inducible factor HIF-1alpha. Cancer Res 70: 10351-10361, 2010.

26. Hong SS, Lee H and Kim KW: HIF-1alpha: A valid therapeutic target for tumor therapy. Cancer Res Treat 36: 343-353, 2004

27. Hameiri-Grossman M, Porat-Klein A, Yaniv I, Ash S, Cohen IJ, Kodman Y, Haklai R, Elad-Sfadia G, Kloog Y, Chepurko E, et al: The association between let-7, RAS and HIF-1 $\alpha$ in Ewing Sarcoma tumor growth. Oncotarget 6: 33834-33848, 2015.

28. Shih $\mathrm{C}$ and Weinberg RA: Isolation of a transforming sequence from a human bladder carcinoma cell line. Cell 29: 161-169, 1982.

29. Haliassos A, Liloglou T, Likourinas M, Doumas C, Ricci N and Spandidos D: H-ras oncogene mutations in the urine of patients with bladder-tumors - description of a noninvasive method for the detection of neoplasia. Int J Oncol 1: 731-734, 1992.

30. Zhang $\mathrm{X}$ and Zhang Y: Bladder cancer and genetic mutations. Cell Biochem Biophys 73: 65-69, 2015.

31. Kompier LC, Lurkin I, van der Aa MN, van Rhijn BW, van der Kwast TH and Zwarthoff EC: FGFR3, HRAS, KRAS, NRAS and PIK3CA mutations in bladder cancer and their potential as biomarkers for surveillance and therapy. PLoS One 5: e13821, 2010.

32. Beukers W, Hercegovac A and Zwarthoff EC: HRAS mutations in bladder cancer at an early age and the possible association with the Costello Syndrome. Eur J Hum Genet 22: 837-839, 2014. 
33. Pandith AA, Shah ZA, Khan NP, Baba KM, Wani MS and Siddiqi MA: HRAS T81C polymorphism modulates risk of urinary bladder cancer and predicts advanced tumors in ethnic Kashmiri population. Urol Oncol 31: 487-492, 2013.

34. Goldberg L, Israeli R and Kloog Y: FTS and 2-DG induce pancreatic cancer cell death and tumor shrinkage in mice. Cell Death Dis 3: e284, 2012.

35. Goldberg L, Ocherashvilli A, Daniels D, Last D, Cohen ZR, Tamar G, Kloog Y and Mardor Y: Salirasib (farnesyl thiosalicylic acid) for brain tumor treatment: A convection-enhanced drug delivery study in rats. Mol Cancer Ther 7: 3609-3616, 2008.

36. Charette N, De Saeger C, Lannoy V, Horsmans Y, Leclercq I and Stärkel P: Salirasib inhibits the growth of hepatocarcinoma cell lines in vitro and tumor growth in vivo through ras and mTOR inhibition. Mol Cancer 9: 256, 2010.
37. Kurzrock R, Kantarjian HM, Blascovich MA, Bucher C, Verstovsek S, Wright JJ, Pilat SR, Cortes JE, Estey EH, Giles FJ, et al: Phase I study of alternate-week administration of tipifarnib in patients with myelodysplastic syndrome. Clin Cancer Res 14: 509-514, 2008.

38. Lancet JE, Gojo I, Gotlib J, Feldman EJ, Greer J, Liesveld JL, Bruzek LM, Morris L, Park Y, Adjei AA, et al: A phase 2 study of the farnesyltransferase inhibitor tipifarnib in poor-risk and elderly patients with previously untreated acute myelogenous leukemia. Blood 109: 1387-1394, 2007.

39. Welsch ME, Kaplan A, Chambers JM, Stokes ME, Bos PH, Zask A, Zhang Y, Sanchez-Martin M, Badgley MA, Huang CS, et al: Multivalent small-molecule Pan-RAS inhibitors. Cell 168: 878-889.e29, 2017. 